\title{
Inhibition of anodic dissolution of Mg90 alloy by adsorption layers of higher carboxylic acids
}

\section{V.A. Ogorodnikova,* Yu.I. Kuznetsov, A.A. Chirkunov and A.M. Semiletov}

A.N. Frumkin Institute of Physical Chemistry and Electrochemistry, Russian Academy of Sciences, Leninsky pr. 31, Moscow, 119071 Russian Federation

*E-mail: masildik@mail.ru

\begin{abstract}
The passivating ability of thin adsorption films of oleic acid and its sodium salt previously formed on the surface of technical magnesium from ethanolic solutions was studied in borate buffer $(\mathrm{pH}$ 9.2) containing aggressive sodium chloride. Analysis of the anodic polarization curves showed that the adsorption protective films formed in an ethanolic solution of oleic acid are more stable than the films of stearic and tridecanoic acids or sodium oleate, which exhibits much more efficient passivating properties upon adsorption from aqueous solutions.

Measurements of the wetting contact angle $\left(\Theta_{c}\right)$ on magnesium samples pre-oxidized and treated with ethanolic solutions of carboxylic acids showed that short-term treatment of $\mathrm{Mg}$ in oleic acid solution, even with $C_{\text {in }}=16 \mathrm{mM}$, does not hydrophobize its surface, although it increases the value of the $\Theta_{c}$ angle in time. However, after immersing the electrode in this solution for 15 hours and then washing it with pure ethanol, the value of $\Theta_{c}$ is $93 \pm 1^{\circ}$, although this value is lower than $\Theta_{c}=115^{\circ}$ measured on the coating formed by the more hydrophobic stearic acid in a much shorter period $(10 \mathrm{~min})$. Oleic acid is inferior in the hydrophobizing effect not only to stearic acid but also to the less hydrophobic tridecanoic acid. However, it is possible to enhance the hydrophobization of magnesium surface by formulations of oleic acid with other higher carboxylic acids by means of relatively long treatment in an ethanolic solution.
\end{abstract}

Received: June 25, 2018. Published: June 28, 2018

doi: $\underline{10.17675 / 2305-6894-2018-7-2-11}$

Key words: magnesium, corrosion inhibitors, carboxylic acids.

\section{Introduction}

Magnesium is the lightest engineering metal with a density of $\sim 1.7 \mathrm{~g} / \mathrm{cm}^{3}$, which is much lower than for other metals common in the industry (for example, $\mathrm{Al}-2.7$ and $\mathrm{Fe}-$ $7.9 \mathrm{~g} / \mathrm{cm}^{3}$ ) [1]. In view of the need to improve the strength characteristics, $\mathrm{Mg}$ is doped by addition of various components [2]. Mg alloys have the highest strength/mass ratio, which makes them particularly attractive for use in the automotive and aeronautical industries. According to Esmaily et al. [3], reduction in the mass of an aircraft by $1 \mathrm{~kg}$ leads to fuel savings of $\$ 1150$ during its operating time. Economic benefits, along with emission targets 
in different countries, are the driving force for the spread of lightweight structural materials. Other advantages of $\mathrm{Mg}$ are its relative safety for the environment and nontoxicity for humans, ease of processing by high-speed milling and turning [2-4]. Mg alloys have an excellent casting ability, which makes it possible to fabricate complex shapes using high-performance methods such as high-pressure casting.

However, despite the great advantages of $\mathrm{Mg}$ alloys, alloying does not save them from low corrosion resistance. The traditional method of anticorrosive protection of magnesium alloys is the deposition of chromate conversion coatings on them, as they provide long-term protection against corrosion and possess the property of "self-healing" $[1,5]$. Unfortunately, coatings based on chromates and $\mathrm{Cr}(\mathrm{VI})$ compounds have a negative impact on human health and the environment, therefore their use for corrosion protection is restricted or prohibited, especially in the European Union [6]. In view of this, the development of alternative, environmentally friendly methods and means of forming protective layers and coatings on metals, including $\mathrm{Mg}$ and its alloys, is an urgent task that corrosion science must solve.

Among the reasons causing the low anticorrosive resistance of $\mathrm{Mg}$ and its alloys, one can distinguish their high reactivity due to the high electronegative $\mathrm{Mg}$ potential and the low barrier properties of oxide-hydroxide layers formed on their surfaces in neutral environments. They are soluble in most aqueous solutions or in moisture films formed on the metal surface from the atmosphere. Corrosion of alloys is accelerated by impurities of less electronegative metals and the presence of corrosive ions on their surfaces, in particular chlorides, sulfates, etc. The high degree of defectiveness of oxide-hydroxide surface layers on $\mathrm{Mg}$ and its alloys causes the need for additional treatment of the oxide [7].

In this treatment, the leading place belongs to organic inhibitors of $\mathrm{Mg}$ corrosion, among which carboxylic acids and their salts play an important role [8]. They have long been successfully used to protect various metals and alloys in aqueous or aqueous-organic solutions and to prevent atmospheric corrosion [9, 10]. Not surprisingly, inhibitors of this type have attracted the attention of researchers for the protection of $\mathrm{Mg}$ alloys over the past decades. For instance, Steinmetz et al. [11] found that sodium undecanoate was the most effective inhibitor of the corrosion of a $\mathrm{Mg}$ alloy $(15 \% \mathrm{Al}, 3 \% \mathrm{Zn})$ in a cooling water with $\mathrm{pH} 8.0$ among the sodium salts of $\mathrm{C}_{7-12}$ alkylcarboxylic acids. The protective effect of the inhibitor was explained by its ability to form a layer of a water-insoluble salt $\mathrm{Mg}\left(\mathrm{CH}_{3}\left[\mathrm{CH}_{2}\right]_{9} \mathrm{COO}\right)_{2}$ on the alloy surface. Later, Liu et al. [12] showed that the selfassembled monolayers (SAM) formed by salts of carboxylic acids $\left(\mathrm{C}_{n-1} \mathrm{H}_{2 n-1} \mathrm{COONa}, n=\right.$ $12,16,18)$ in ethanolic solution on AZ91D Mg alloy (Al 8.3-9.7\%) hydrophobized its surface and significantly slowed down the corrosion in aqueous $0.2 \mathrm{M} \mathrm{NaCl}$ solution. The protection efficiency $(Z)$ determined by electrochemical impedance spectroscopy (EIS) increased with the alkyl length and the duration of preliminary exposure of the sample in the ethanolic solution of the passivator $(\tau)$. The best protection $(Z=98.5 \%)$, like the hydrophobizing effect, was observed in the case of sodium stearate and at $\tau=96 \mathrm{~h}$. 
A similar conclusion was reached by Italian researchers who studied the protective effect of sodium salts of alkylcarboxylic acids (with 7-15 carbon atoms) in model cooling water with $\mathrm{pH} 8.1$ [13] and of some anionic surfactants (sodium salts of N-laurylsarcosine (NLS), N-lauryl-N-methyltaurine (NLT), dodecylbenzenesulfonic acid (DBS), or lauryl sulfonic acid) in $0.1 \mathrm{M} \mathrm{NaCl}$ or $\mathrm{Na}_{2} \mathrm{SO}_{4}$ solutions [14]. They related the protection of the AZ31 magnesium alloy with the deposition of an insoluble $\mathrm{Mg}$ salt on its surface, which slows its anodic dissolution and corrosion.

The studies mentioned above showed that salts of higher carboxylates could be effective passivating agents of $\mathrm{Mg}$ and its alloys, at least in nearly-neutral environments. Of particular interest is the non-toxic and economically accessible stearic acid $\mathrm{CH}_{3}\left(\mathrm{CH}_{2}\right)_{16} \mathrm{COOH}$ (SA). Since $\mathrm{Mg}$ is a convenient metallic material for degradable orthopedic implants that are capable of maintaining sufficient mechanical integrity in the initial period of bone healing, the study of stearates as a non-toxic corrosion inhibitor of $\mathrm{Mg}$ alloys has received an additional stimulus. In order to increase its protective effect, a two-step treatment of $\mathrm{Mg}$ (with a purity of 99.96\%) was suggested [4]. In the first step (hydrothermal treatment: $t=120^{\circ} \mathrm{C}, \tau=24 \mathrm{~h}$ ), a thick layer of hydroxide is formed, which ensures the fixation of the SA coating. In the second stage, $\mathrm{Mg}$ with a hydroxide layer is treated by SA to form a coating of $\mathrm{Mg}$ stearate. This is achieved by submerging the samples for $2 \mathrm{~h}$ into a $1.5 \mathrm{M}$ solution $\mathrm{SA}$ in chloroform at $50^{\circ} \mathrm{C}$ or into a melt (at 100 or $150^{\circ} \mathrm{C}$ ). Corrosion behavior of coated samples was studied by electrochemical methods in a Hanks solution simulating the body fluid. The corrosion resistance of the coated samples was much higher than that of the bare $\mathrm{Mg}$, especially in the initial period, due to the barrier effect provided by the coating. The best protective effect was obtained after immersion of the samples into an SA melt with $t=100^{\circ} \mathrm{C}$. Degradation of the coating occurred due to cracking upon prolonged immersion (80 days), with formation of $\mathrm{Mg}(\mathrm{OH})_{2}$ and apatite.

In recent years, studies of the interaction of SA (or its salt) with $\mathrm{Mg}$ were continued and its advantages in protecting other alloys such as $\mathrm{ZE} 41(\mathrm{Li}-\mathrm{Mg})$ with stearate compared with palmitate and sodium myristate [15] were confirmed, along with the possibility of hydrophobization [16] and super-hydrophobization of pure $\mathrm{Mg}$ [17]. The search for better methods of applying hydrophobic coatings to magnesium alloys [18] and more effective corrosion inhibitors [19] is continuing.

The effect of sodium salts of higher carboxylic acids such as lauric, oleic (SOL), linolenic and oleilsarcosine on the anodic dissolution of technical magnesium Mg-90 in a borate buffer solution with $\mathrm{pH} 7.4$ was also studied in our laboratory [19]. It was shown that the best protection efficiency under these conditions is provided by SOL and that treatment with its aqueous solution is superior to chromate passivation.

Recently we used the in situ ellipsometric method to measure the adsorption of SOL on oxidized $\mathrm{Mg}$ from a borate solution with $\mathrm{pH} 11.2$ [20]. It was shown that in the range of average coverages, it is adequately described by the Temkin equation with a high standard adsorption energy $\left(-\Delta G_{\mathrm{A}}^{0}\right)=55 \pm 3 \mathrm{~kJ} / \mathrm{mol}$ and the energy inhomogeneity coefficient of 
the surface $f=4.1 \pm 0.2$. This made it possible to assume that SOL is chemisorbed on $\mathrm{Mg}$ and that the orientation of the organic anion on the electrode surface is nearly vertical. It was also observed that preliminary short-term exposure of the electrode in an ethanolic solution of SA is much inferior in inhibiting the anodic dissolution of $\mathrm{Mg}$ to its similar passivation with an aqueous solution of SOL. Taking into account the low toxicity and lower hydrophobicity of oleic acid in comparison with SA, it is of interest to continue studies on the effect of both acids on the anodic dissolution of magnesium.

The purpose of this article is to study the effect of adsorption layers of some higher carboxylic acids on the anodic behavior of technical magnesium in a borate buffer solution (pH 9.2).

\section{Experimental technique}

Electrochemical studies were carried out on technical grade magnesium (Mg-90) samples, $\%$ : Mg, 99.9; $\mathrm{Fe}<0.04 ; \mathrm{Mn}<0.03 ; \mathrm{Al}<0.02 ; \mathrm{Ni}<0.001 ; \mathrm{Cu}<0.004 ; \mathrm{Si}<0.009$; and $\mathrm{Cl}<0.005$. Electrochemical measurements were performed using cylindrical electrodes with a working area of $0.75 \mathrm{~cm}^{2}$ embedded in epoxy resin. A borate buffer solution (pH 9.2) containing $1 \mathrm{mM} \mathrm{NaCl}$ served as the background solution. Polarization curves of $\mathrm{Mg}$ were recorded in a glass cell with separated electrode spaces using an IPC-Pro MF potentiostat. The $\mathrm{Mg}$ potentials $(E)$ were measured relative to the silver chloride electrode and recalculated to the normal hydrogen scale. Platinum served as the auxiliary electrode.

The following carboxylic acids were used: oleic $\mathrm{C}_{17} \mathrm{H}_{33} \mathrm{COOH}$ (OLA), $\mathrm{C}_{17} \mathrm{H}_{35} \mathrm{COOH}$ (SA), and tridecanoic acid $\mathrm{C}_{12} \mathrm{H}_{25} \mathrm{COOH}$ (TDA) that also contains a long hydrocarbon chain but is inferior in hydrophobicity to OLA and especially SA [2].

Electrodes for polarization studies were prepared in two ways. In one of them, the electrode was polished on sandpapers with various grades and degreased with acetone, then the electrode was held for $10 \mathrm{~min}$ in an inhibitor solution and dried for 60 minutes in air. In another method, the polished and degreased electrode was oxidized for $1.5 \mathrm{~h}$ in a $5.0 \mathrm{M}$ $\mathrm{NaOH}$ solution, then washed with distilled water and dried for $60 \mathrm{~min}$ in air. The dried oxidized electrode was kept for $10 \mathrm{~min}$ in an inhibitor solution and air dried again. After preparation, the sample was immersed in the background solution and anodic polarization was immediately started with a scan rate of $0.2 \mathrm{mV} / \mathrm{s}$.

Measurements of the wetting contact angle $\left(\Theta_{\mathrm{c}}\right)$ were carried out on rectangular $\mathrm{Mg}$ plates measuring $20 \times 30 \times 8 \mathrm{~mm}$. The plates were preliminarily polished on sandpaper and degreased with acetone. Samples were oxidized in $5 \mathrm{M} \mathrm{NaOH}$, then treated in ethanolic solutions of inhibitors or mixtures thereof $\left(C_{\mathrm{in}}=16 \mathrm{mM}\right)$. To measure the $\Theta_{\mathrm{c}}$, a video image of a drop of distilled water was obtained on the surface under investigation using an experimental laboratory unit with a built-in DCM 300 camera. The droplet volume was 3$4 \mu \mathrm{l}$. The $\Theta_{\mathrm{c}}$ value was determined from image using the PicPick graphic editor. In order to obtain a reliable wetting behavior for the coatings, the initial $\Theta_{c}$ was measured 5-10 s after the drop was placed at 5 different surface points of each sample. The mean $\Theta_{c}$ value was 
determined from 5 consecutive images of the drop. The root-mean-square deviation of $\Theta_{c}$ for these images was $1.5-2^{\circ}$.

\section{Results and Discussion}

If a $\mathrm{Mg}$ electrode does not undergo preliminary alkaline oxidation, it is coated with a thin oxide-hydroxide film that was formed during its cleaning, degreasing and short-term contact with the air atmosphere. When such an electrode is immersed in a borate buffer solution with $\mathrm{pH} 9.2$ containing $1 \mathrm{mmol} / 1 \mathrm{NaCl}$, the dissolution of the metal rapidly increases after anodic polarization is started (Figure 1). Preliminary treatment of the electrode in a $16 \mathrm{mM}$ solution of SA or TDA in ethanol increases its initial potential $E_{\mathrm{i}}$ by $0.25 \mathrm{~V}$ and $0.41 \mathrm{~V}$, respectively. However, a rapid increase in current is also observed due to intense $\mathrm{Mg}$ dissolution upon anodic polarization of the electrode. After the electrode was removed from the solution, it was found that its surface did not lose its luster, but dark dots appeared on it, indicating a weak protective effect of the adsorption layer.

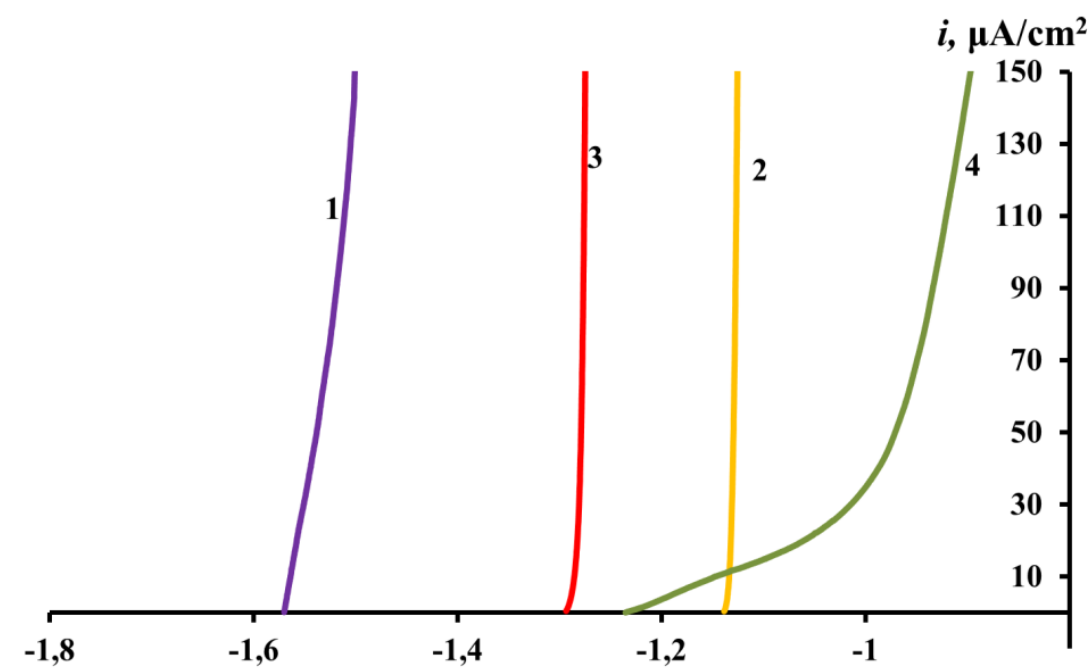

$E, \mathrm{~V}$

Figure 1. Anodic polarization curves of $\mathrm{Mg} 90$ alloy in borate buffer with $\mathrm{pH} 9.2$ containing $1.0 \mathrm{mM} \mathrm{NaCl}$ without (1) and after preliminary adsorption from $16 \mathrm{mM}$ solutions of higher carboxylic acids in ethanol for 10 min: 2 - TDA, 3 - SA, 4 - OLA.

A similar treatment of a Mg electrode in an ethanolic solution of OLA demonstrates a much greater inhibition of its anodic dissolution, although $\log P$ for OLA is 7.7, i.e., it is higher than that of TDA (5.56) but lower than that of SA (8.23). An area with small current densities can be identified on the anodic polarization curve, which indicates the passivating action of the adsorption layers of OLA.

If a $\mathrm{Mg}$ electrode is oxidized in an alkaline solution, it is coated with a film that is thicker than the oxide-hydroxide layer formed in air. The $E_{\mathrm{i}}$ value of this electrode after immersion in a borate buffer containing $1.0 \mathrm{mM} \mathrm{NaCl}$ is noticeably less negative $(-1.127$ 
instead of $-1.57 \mathrm{~V}$ ) than in the case of non-oxidized $\mathrm{Mg}$ (Figure 2). A similar displacement of $E_{\mathrm{i}}$ to less negative values also occurs in the case of oxidized $\mathrm{Mg}$ treated with solutions of carboxylic acids. Here, the passivating effect of the adsorption layers of not only OLA but also SA and the weakest passivator - TDA becomes noticeable. It is accompanied by a significant decrease in the anodic current density in the initial section of the anodic polarization curve and an increase in its length as compared with that of a non-oxidized electrode. This indicates the advantage of strong adsorption, at least of OLA and SA, on the oxidized surface of $\mathrm{Mg}$.

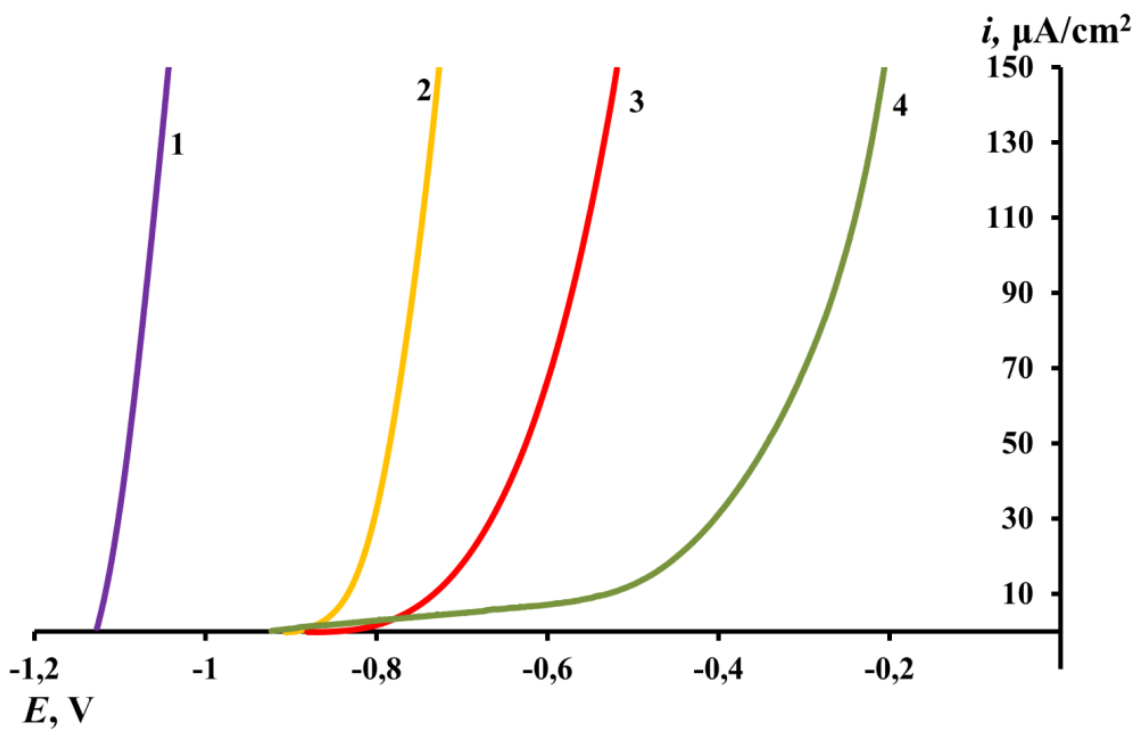

Figure 2. Anodic polarization curves of chemically oxidized Mg90 alloy in borate buffer with $\mathrm{pH} 9.2$ containing $1.0 \mathrm{mM} \mathrm{NaCl}$ without (1) and after preliminary adsorption from $16 \mathrm{mM}$ solutions of higher carboxylic acids in ethanol for 10 min: 2 - TDA, 3 - SA, 4 - OLA.

In view of this, further investigations were mainly carried out on oxidized $\mathrm{Mg}$. It was found that the anodic polarization curve of the electrode immersed for $10 \mathrm{~min}$ in an ethanolic solution of OLA with $C_{\mathrm{in}}=4.0 \mathrm{mM}$ differs only a little from the similar curve of oxidized Mg (Figure 3). However, the slope of the polarization curve of the electrode, at which the adsorption of OLA occurred during the same time in the solution with $\mathrm{C}_{\mathrm{in}}=8.0$ $\mathrm{mM}$, increased noticeably. In the case of processing the electrode in a solution with $\mathrm{C}_{\mathrm{in}}=$ $12 \mathrm{mM}$, the polarization curve obtained on it shows a small region near $E_{\mathrm{st}}$, indicating, although still weak, the passivating action of adsorption of OLA. As already noted above, it is enhanced by a similar treatment of the electrode from the solution with $C_{\mathrm{in}}=16 \mathrm{mM}$.

It is interesting that in this case the region of the curve where the passive $\mathrm{Mg}$ state is visible reaches $0.20 \mathrm{~V}$, i.e., practically the same value that is observed after preliminary treatment of the electrode in an aqueous $16 \mathrm{mM}$ solution of SOL (Figure 4). The small difference in the anodic polarization curves $2 *$ and 6 is that the $E_{\mathrm{st}}$ value is less negative for the electrode treated in the ethanolic solution of OLA than in the aqueous solution of SOL. 
The more effective suppression of anodic Mg dissolution by a protective layer formed by adsorption of OLA is also indicated by smaller currents observed on the passive region of the curve and its greater slope with increasing polarization of the electrode.

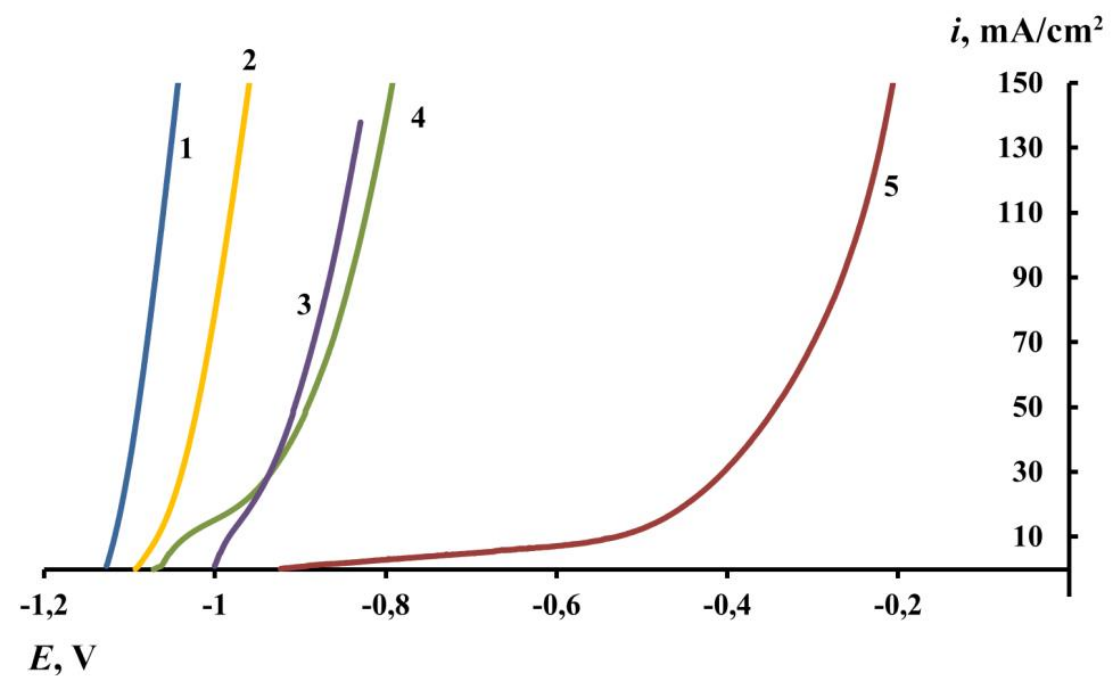

Figure 3. Anodic polarization curves of chemically oxidized $\mathrm{Mg} 90$ alloy in borate buffer with $\mathrm{pH} 9.2$ containing $1.0 \mathrm{mM} \mathrm{NaCl}$ without (1) and after preliminary adsorption for $10 \mathrm{~min}$ from OLA solutions in ethanol (in $\mathrm{mM}$ ): $2-4.0 ; 3-8.0 ; 4-12.0 ; 5-16.0$.

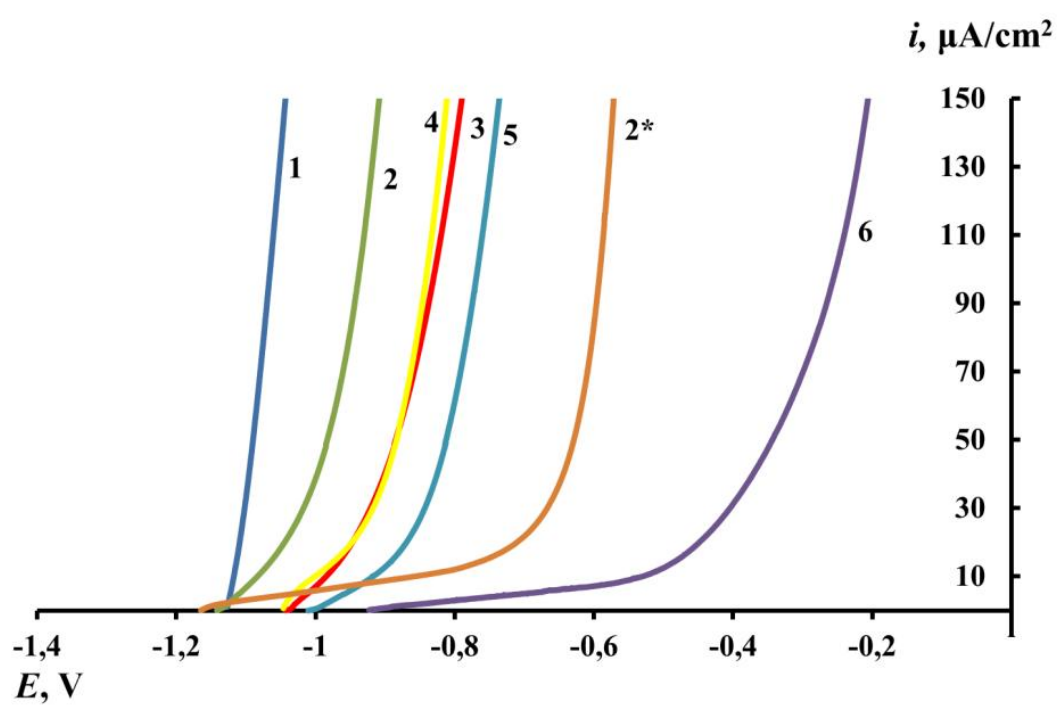

Figure 4. Anodic polarization curves of chemically oxidized Mg90 alloy in borate buffer with $\mathrm{pH} 9.2$ containing $1.0 \mathrm{mM} \mathrm{NaCl}$ without (1) and after preliminary adsorption of inhibitors (2$6,2 *)$. The adsorption of OLA, SOL, or mixtures thereof was performed by 10 min electrode immersion in aqueous $(2 *)$ and ethanolic solutions (2-6) containing (in $\mathrm{mM}$ ): $2,2 *-16$ SOL; $3-4$ OLA + 12 SOL; $4-8$ OLA + 8 SOL $; 5-12$ OLA + 4 SOL; $6-16$ OLA.

It is significant that in the ethanolic solution (16 mm SOL) a much less stable protective layer is formed than in the aqueous solution. Replacement of SOL by OLA 
(curves 3-5 in Figure 4) improves the inhibitory effect, the stronger the higher the OLA content in the mixture, but still does not provide the stability of the protective layer formed by SOL adsorption from the aqueous solution, let alone in the case of the layer formation in the ethanolic solution of OLA itself.

An explanation of the observed effects of inhibiting the anodic dissolution and passivation of $\mathrm{Mg}$ by adsorption of $\mathrm{OlK}$ and its salt requires additional studies, primarily with a longer formation of the protective layer. Let us note that the results of the measurement of $\Theta_{c}$ after such a short-term formation of a protective film in the ethanolic solution of OLA itself (Figure 5) show its increase with time. However, if no washing with ethanol is performed, the film remains hydrophilic even after 15 hours. After such washing that removes the weakly adhering molecules of the organic acid, and possibly its magnesium salts, from the electrode, the value of $\Theta_{c}$ exceeds $90^{\circ}$. Hydrophobization of the "washed" Mg surface indicates the continuing self-organization of the most strongly associated adsorption layer.

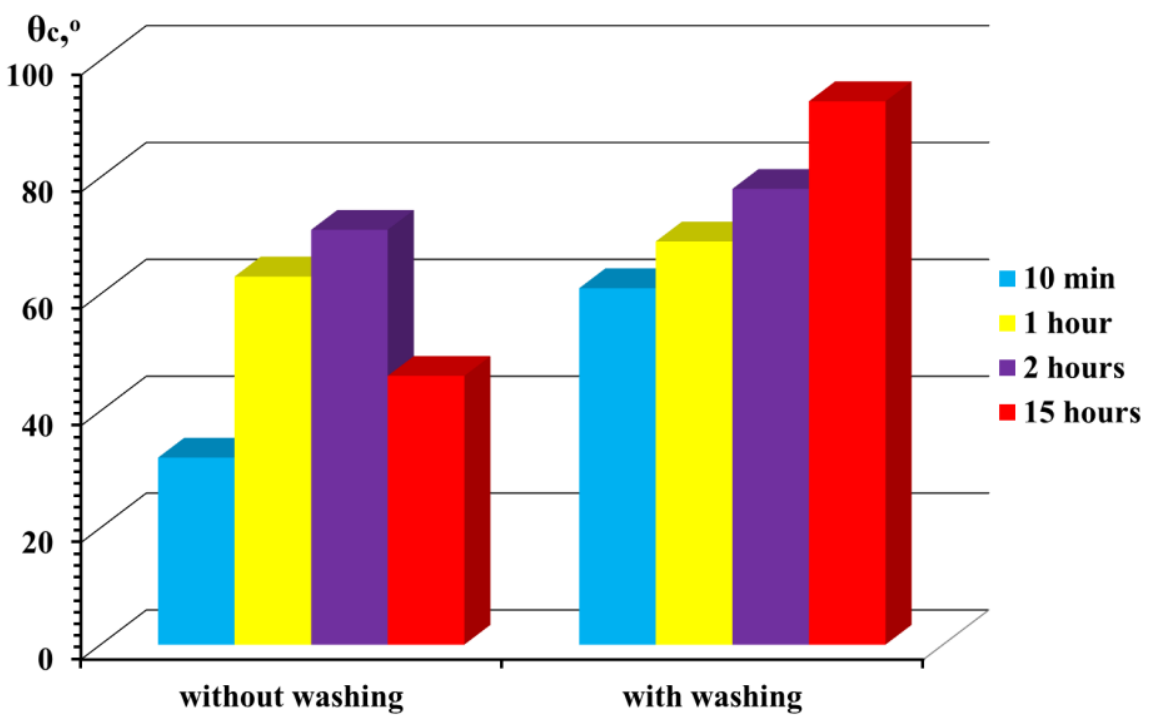

Figure 5. Dependence of the wetting contact angle $\Theta_{c}$ on the surface of a chemically oxidized plate of Mg90 alloy on the time of immersion in a $16 \mathrm{mM}$ OLA solution in ethanol.

It is not surprising that the value of $\Theta_{c}$, which is often used as a characteristics of the self-organization of surfactants, remains lower for an ultrathin adsorption coating of OLA even after washing the $\mathrm{Mg}$ surface with ethanol than the $\Theta_{c}$ value measured on a coating formed by a more hydrophobic SA in a shorter period $(10 \mathrm{~min})$. Its value $\left(\Theta_{c}=115^{\circ}\right)$ confirms the well-known fact of better self-organization of alkylcarboxylic acids in comparison with their analogs containing unsaturated hydrocarbon chains. The coatings formed in ethanolic solution in $1 \mathrm{~h}$ and $15 \mathrm{~h}$ by TDA, which is less hydrophobic than OLA and has a shorter alkyl, are characterized by $\Theta_{c}=110^{\circ}$ and $112^{\circ}$, respectively, and after washing with ethanol, $\Theta_{c}=102^{\circ}$ and $110^{\circ}$, respectively. Interestingly, prolonged treatment 
(15 h) of $\mathrm{Mg}$ in $16 \mathrm{mM}$ ethanolic solution of an equimolar TDA + OLA mixture followed by washing in ethanol produces a nanoscale coating with $\Theta_{\mathrm{c}}=114^{\circ}$. Hence, the best $\mathrm{Mg}$ passivator, i.e., OLA, when combined with the best hydrophobizers, can form more waterresistant coatings. Hence, it can be expected that further studies will improve the protective ability of nanoscale layers of non-toxic higher carboxylic acids and improve the methods for their production.

\section{Conclusions}

1. The adsorption of non-toxic OLA and its salt, SOL, is capable of forming thin films on the surface of technical $\mathrm{Mg}$ that prevent its dissolution in a weakly alkaline borate buffer (pH 9.2) containing corrosive sodium chloride. Protective films formed in ethanolic solution are more stable in the case of OLA than SA, TDA or SOL, which exhibits much more efficient passivating properties when adsorbed from an aqueous solution.

2. Short-term treatment of oxidized $\mathrm{Mg}$ in an ethanolic solution, even at $C_{\text {in }}=16 \mathrm{mM}$ OLA, does not hydrophobize its surface, although it increases the value of the contact angle $\Theta_{c}$ in time. However, after immersing the electrode for $15 \mathrm{~h}$ in this solution and followed by washing with pure ethanol, $\Theta_{c}>90^{\circ}$, although this value is lower than $\Theta_{c}=115^{\circ}$ measured on the coating formed by the more hydrophobic SA in a much shorter period (10 $\mathrm{min})$.

3. OLA is inferior in the hydrophobizing effect not only to SA, but also to the less hydrophobic TDA. However, by a relatively long treatment of $\mathrm{Mg}$ in an ethanolic solution, it is possible to enhance the hydrophobization of its surface by formulations of OLA with other higher carboxylic acids.

\section{Acknowledgements}

This study was financially supported by RFBR grant No. 16-03-00199 "Modification of the surface of $\mathrm{Al}, \mathrm{Mg}$ and their alloys by nanoscale organic corrosion inhibitors".

\section{References}

1. K.U. Kainer, Magnesium Alloys and Technology, John Wiley \& Sons, 2003.

2. M.M. Avedesian and H. Baker, ASM Specialty Handbook: Magnesium and Magnesium Alloys, ASM International, 1999.

3. M. Esmaily, J.E. Svensson, S. Fajardo, N. Birbilis, G.S. Frankel, S. Virtanen, R. Arrabal, S. Thomas and L.G. Johansson, "Fundamentals and Advances in Magnesium Alloy Corrosion", Prog. Mater. Sci., 2017, 89, 92-193. doi: 10.1016/j.pmatsci.2017.04.011

4. W.F. Ng, M.H. Wong and F.T. Cheng, "Stearic acid coating on magnesium for enhancing corrosion resistance in Hanks' solution", Surf. Coat. Technol., 2010, 204, no. 11, 1823-1830. doi: 10.1016/j.surfcoat.2009.11.024 
5. N.S. Grigoryan, E.F. Akimova and T.A. Vagramyan, Phosphating (Fosfatirovanie), Moscow, Globus, 2008, 144 pp. (in Russian).

6. S. Szillies, P. Thissend, D. Tabatabai, F. Feil, W. Fürbeth, N. Fink and G. Grundmeier, "Formation and stability of organic acid monolayers on magnesium alloy AZ31. The role of alkyl chain length and head group chemistry", Appl. Surf. Sci., 2013, 283, 339347. doi: $10.1016 /$ j.apsusc.2013.06.113

7. K. Gusieva, C.H.J. Davies, J.R. Scully and N. Birbilis, "Corrosion of magnesium alloys: the role of alloying", Int. Mater. Rev., 2015, 60, no. 3, 169-194. doi: 10.1179/1743280414Y.0000000046

8. Yu.I. Kuznetsov, "Organic corrosion inhibitors: where are we now? A review. Part II. Passivation and the role of chemical structure of carboxylates," Int. J. Corros. Scale Inhib., 2016, 5, no. 4, 282-318. doi: 10.17675/2305-6894-2016-5-4-1

9. Yu.I. Kuznetsov, "Organic Inhibitors of Corrosion of Metals”, New York, Plenum Press, 1996, 283 pp.

10. A.A. Mikhailov, Yu.M. Panchenko and Yu.I. Kuznetsov, "Atmospheric corrosion and protection of metals" (Atmosfernaya korroziya i zaschita metallov), Tambov, Pershin Publishing House, 2016, 555 pp. (in Russian).

11. D. Daloz, C. Rapin, P. Steinmetz and G. Michot, "Corrosion Inhibition of Rapidly Solidified Mg-3\% Zn-15\% Al Magnesium Alloy with Sodium Carboxylates", Corrosion, 1998, 54, 444-450. doi: 10.5006/1.3284872

12. Y. Liu, Z. Yu, S. Zhou and L. Wu, "Self-assembled monolayers on magnesium alloy surfaces from carboxylate ions", Appl. Surf. Sci., 2006, 252. 3818-3827. doi: 10.1016/j.apsusc.2005.05.072

13. F. Zucchi, V. Grassi and F. Zanotto, "Sodium monocarboxylates as inhibitors of AZ31 alloy corrosion in a synthetic cooling water", Mater. Corros., 2009, 60, no. 3, 199-205. doi: $10.1002 / \mathrm{maco} .200805045$

14. A. Frignani, V. Grassi, F. Zanotto and F.Zucchi, "Inhibition of AZ31 Mg alloy corrosion by anionic surfactants", Corros. Sci., 2012, 63, 29-39. doi: 10.1016/j.corsci.2012.05.012

15. N. Dinodi and N. Shetty, "Alkyl carboxylates as efficient and green inhibitors of magnesium alloy ZE41 corrosion in aqueous salt solution", Corros. Sci., 2014, 85, 411-427. doi: $10.1016 / \mathrm{j}$. corsci.2014.04.052

16. L. Oiao, Y. Wang, M. Mohedano, C. Gong and J. Gao, "The Preparation and Corrosion Performance of Self-Assembled Monolayers of Stearic Acid and $\mathrm{MgO}$ Layer on Pure Magnesium", Mater. Trans., 2014, 55, no. 8, 1337-1343.

17. Ya. Wang, W. Wang, L. Zhong, J. Wang, Q. Jiang and X. Guo, "Super-hydrophobic surface on pure magnesium substrate by wet chemical method", Appl. Surf. Sci., 2010, 256, 3837-3840. doi: 10.1016/j.apsusc.2010.01.037

18. Yu. Zhang, C. Blawert, Sh. Tang, J. Hu, M. Mohedano, M.L. Zheludkevich and K.U. Kainer, "Influence of surface pre-treatment on the deposition and corrosion 
properties of hydrophobic coatings on a magnesium alloy", Corros. Sci., 2016, 112, 483-494. doi: $10.1016 /$ j.corsci.2016.08.013

19. A.M. Semiletov, Yu.I. Kuznetsov and A.A. Chirkunov, "Inhibition of Magnesium Corrosion by Salts of Higher Carbonic Acids", Prot. Met. Phys. Chem. Surf., 2017, 53, no. 7, 1215-1220. doi: $10.1134 / \mathrm{S} 2070205117070152$

20. V.A. Ogorodnikova, Yu.I. Kuznetsov, N.P. Andreeva and A.A. Chirkunov, "Adsorption of sodium oleate from alkaline solutions on oxidized magnesium" (Adsorbtsiya oleata natriya iz shchelochnykh rastvorov na okislennom magnii), Korroz.: mater., zashch., 2018, no. 5, 27-31 (in Russian)

21. C. Hanch and A. Leo, Substituent Constants for Correlation Analysis in Chemistry and Biology, Wiley-Interscience, New York, 1979, 339 pp. 